\title{
PROMOTING HEALTH IN RURAL TRANSYLVANIA, ROMANIA. A DESCRIPTIVE ANALYSIS OF HEALTH PROMOTION ACTIVITIES
}

\author{
Cătălin O. Baba, Alexandra Brînzaniuc, Emanuela O. Şirlincan, Răzvan M. Cherecheş \\ Center for Health Policy and Public Health, Faculty of Political, Administrative and Communication Sciences, Babeş-Bolyai University Cluj- \\ Napoca, Romania
}

\begin{abstract}
SUMMARY
Even though efforts are made to reduce health disparities, promote health for all social groups and improve health outcomes, inconsistencies still exist. Existing evidence shows that lack of funding, lack of properly trained workforce, as well as heavy workload on health care workers, are the most employed explanations for the limited number of health promotion interventions in the area. This paper presents the results of a descriptive study that pursues to render a comprehensive image of health promotion efforts undertaken in rural Transylvania, Romania. This descriptive analysis is conducted on data extracted from a larger dataset, obtained through a study which pursues a cross-sectional design, with a quantitative strategy of inquiry on access to health information in rural Transylvania. The instrument used for data collection is a questionnaire administered by telephone to a sample of medical doctors working in rural medical offices in the studied area $(n=226)$. Results show overall low rates of health promotion activities in the area, as well as low levels of collaboration with other local actors. In the context of behavioral risk factors, this study clearly shows the need of targeted health promotion activities in rural Transylvania in order to improve health outcomes and mitigate health disparities.
\end{abstract}

Key words: health promotion, rural, Transylvania, Romania, access

Address for correspondence: A. Brînzaniuc, 71 Traian Mosoiu St., 400132, Cluj-Napoca, Romania. E-mail: a-brinzaniuc@healthpolicy.ro

\section{INTRODUCTION}

Health is an important dimension of quality of life, and is determined by an array of socio-economic, cultural, environmental, behavioral and biological factors (1). Health promotion is critical in the advancement of public health; it is most commonly defined as the process which enables individuals to increase control over their health, as well as offers instruments for improving it (2). Even though efforts are made in reducing health disparities, promote health for all social groups and improve health outcomes, inconsistencies still exist. The Jakarta Declaration on Leading Health Promotion in the 21st Century draws the priorities for health promotion, which are the promotion of social responsibility for health, increasing investments in health development, consolidation and expansion of partnerships for health, increased community capacity and empowerment, and finally the development of a health promotion infrastructure (3).

There is a health divide between Western and Eastern European Union countries, in terms of overall mortality and morbidity rates (4). In Romania, the life expectancy at birth was 72.69 years in 2006, with 7.62 years below the EU 15 average, and with a probability of dying before the age of 5 of 16.48 per 1,000 live births, which is 3.48 times higher than the EU 15 average (5). High neonatal and perinatal deaths, 7.74 (EU 15:2.7) respectively 10 (EU 15: 5.94) per 1,000 live births, as well as high maternal death rates of 15.49 per 100,000 live births are observed, while the EU 15 average is 5.43 (5). The major causes of mortality are ischemic heart disease, cerebrovascular diseases, hypertensive heart disease, diseases of the respiratory system, as well as malignant tumors (5). Furthermore, external causes of mortality like injuries and poisonings still account for a significant number of yearly deaths and disabilities (6).

Risk behaviors are still at alarming levels, with a per capita alcohol consumption among adults of 9.7 liters of pure alcohol in 2003, as well as a smoking prevalence of 24.5 among women and 40.6 among men in 2005 (7). Modifiable risk behaviors are significant while they constitute burdens on the individual, as well as on the healthcare system. Studies show that physical inactivity, increased body mass index, smoking status, and history of tobacco use have an impact on short-terms healthcare charges (8) as well as long-term health effects (9). Even so, most eastern European countries lack the needed infrastructure or capacity needed for a sustainable development of health promotion interventions to tackle health risks, especially limited resources health systems like the one of Romania.

The World Health Organization (WHO) urges all member states to develop evidence-based approaches to health promotion, as well as increase investments, infrastructure and community capacity in this sense (10). However, developing evidence-based programs to strengthen health promotion is hard to accomplish with a limited body of country-specific research on this topic. This is the case in Romania, where available evidence on health promotion practices, needs and infrastructure is scarce.

In Romania, the Ministry of Public Health's National Program for Prevention lays the guiding principles for health promotion in this country. It is structured into three subprograms, The Public 
Health Subprogram, the Non-communicable Diseases Subprogram, and the Women's and Children's Health Subprogram. Each of them draw lines of action in the field, objectives and responsibilities, whereas the main institutions involved in health promotion activities are defined as the Ministry of Public Health, County Authorities for Public Health, Regional Institutes for Public Health, Hospital Institutions, Family Planning Centers, as well as Primary Care Practices (11). However, existing evidence shows that lack of funding, lack of properly trained workforce, as well as increasing workload on health care workers, are the most employed explanations for the limited number of health promotion interventions in Transylvania, Romania (12). Nevertheless, additional local untapped resources still exist in both rural and urban settings, which could contribute to the development of the health promotion capacity and infrastructure, like the case of libraries in rural and remote settings (13). Hence, more research has to be conducted in this area, in order to provide the scientific community with the collective experience needed to develop health promotion capacity, and ultimately improve population health.

This paper pursues to render a comprehensive image of health promotion efforts, as reported by family physicians, undertaken in rural Transylvania, through structured interviews with key community members. The data is part of a larger dataset collected over a period of 4 months, between June and September 2009 by the Center for Health Policy and Public Health, Babeş-Bolyai University Cluj-Napoca.

\section{MATERIAL AND METHOD}

This descriptive analysis is conducted on data extracted from a larger dataset, obtained through a study which pursues a crosssectional design, with a quantitative strategy of inquiry on access to health information in rural Transylvania. The study unfolds on a representative stratified random sample of 216 communes extracted from the total of 758 communes in the Central and NorthWestern development regions in Romania, in the area historically known as Transylvania. These comprise 12 counties (Alba, Bihor, Bistrița, Brasov, Cluj, Covasna, Harghita, Maramures, Mureş, Satu Mare, Sălaj, Sibiu), accounting for approximately $25 \%$ of the Romanian population.

The instrument used for data collection is a questionnaire administered by telephone, by trained operators, to medical doctors (MD) working in rural medical offices in the studied area $(n=226)$. If multiple primary care doctors operated in the commune, each of them was invited to participate in the study. As a result, the total number of interviewed doctors exceeds the total number of communes, because in 13 of these, two MDs were interviewed. Whenever interviews with the MD were not possible, the medical nurse in the office was interviewed $(n=15)$. Subjects were enrolled in the study only after a trained operator explained the study and its voluntary nature, and attained a verbal consent.

In 3 communes we had total refusals from MDs, resulting in a $1.11 \%$ refusal rate for this sample. We explain this low refusal rate by the socio-cultural context, as well as the data collection protocol which pursued a minimization of refusals. Firstly, in Romania, especially in rural settings, individuals are not enrolled in numerous studies, therefore increasing their willingness to participate when solicited to. Even more, the interviewed subjects proved to be enthusiastic in verbalizing their views towards health promotion practices and/or infrastructure in the environment they operated. Secondly, due to the fact that telephone interviews are flexible, the data collection protocol allowed operators to reschedule the interview at a later date if the respondent decided that the time was not appropriate.

The data collection instrument pursued general information about the practice, number of patients, existing infrastructure, health promotion activities, collaborations with other institutions, as well as tried to identify any health promotion needs and potential necessities for informational materials in the studied rural communities.

\section{RESULTS}

From the total of 226 interviewed subjects, 94 (42.3\%) reported that no health promotion campaigns were developed in their commune, in the previous year. In the same time, $56.3 \%$ of the same respondents have never been involved in the development of and/or developed themselves a health promotion campaign. On the other hand, when asked to estimate the community members interest towards these activities, an overwhelming $77 \%$ reported that they were either interested, very interested or extremely interested (see Table 1).

The existing health promotion activities were mainly organized in rural Transylvania by the Authorities of Public Health - county authorities of public health, in $20.5 \%$ of the cases. Other public institutions were responsible for the health promotion activities in $24.4 \%$ of the cases, non-governmental organizations in $9.4 \%$ of the cases, universities or research institutes in $3.1 \%$ of the cases, or by the local medical doctor office in $11.8 \%$ of the cases.

In terms of the patient's estimated interest towards healthcontent information (see Table 2), only $8.6 \%$ of the respondents reported they have never had patients who solicited additional information on health topics. On the other hand, 51\% reported they "often" or "always" encounter such patients. Furthermore, respondents were asked to estimate how often they feel they need health content informative materials for their patients; thus, $55.9 \%$ have often or always went through such situations, while $44.1 \%$ never or rarely have felt they needed more materials.

Even if a significant number of health promotion activities have been organized in the studied area, only $4.6 \%$ of the doctors have collaborated with the local library in developing such activities. Furthermore, $42.9 \%$ of respondents were not aware if the communal library had collection on health content documents, and only $12.1 \%$ have ever recommended the library as a source of information for patients interested in obtaining more information on health issues. On the other hand, $10 \%$ of doctors ever advised the librarian in the acquisition of health-content documents.

\section{DISCUSSIONS}

More than one third of medical doctors in the studied communities reported that no health promotion campaigns have been developed in the commune they work in, throughout the previous year. In the context of behavioral risk factors described earlier, this study clearly shows the need of targeted health promotion activi- 
Table 1. Health promotion campaigns in rural Transylvania reported by MDs*

\begin{tabular}{|l|c|c|}
\hline & $\mathbf{n}$ & Valid Percent \\
\hline Health Promotion Campaigns in the previous year & & 52.7 \\
\hline Yes & 117 & 42.3 \\
\hline No & 94 & 5 \\
\hline Don't know & 11 & \\
\hline MD involved in any of the campaigns & & 40.1 \\
\hline Yes & 89 & 59.9 \\
\hline No & 133 & \\
\hline Community members interest for health promotion programs & & \\
\hline Not interested & 7 & 18.2 \\
\hline Somewhat interested & 27 & 35.1 \\
\hline Interested & 52 & 29.7 \\
\hline Very interested & 44 & 12.2 \\
\hline Extremely interested & 18 & \\
\hline
\end{tabular}

${ }^{*} \mathrm{MD}$ medical doctors

Table 2. Health-content informative materials

\begin{tabular}{|c|c|c|}
\hline & $\mathrm{n}$ & Valid percent \\
\hline \multicolumn{3}{|c|}{ How often do you have patiens who request additional information on health issues? } \\
\hline Never & 19 & 8.6 \\
\hline Rarely & 89 & 40.5 \\
\hline Often & 89 & 40.5 \\
\hline Always & 23 & 10.5 \\
\hline \multicolumn{3}{|c|}{ How often do you feel the need to offer more health-content materials/documents? } \\
\hline Never & 37 & 16.8 \\
\hline Rarely & 60 & 27.3 \\
\hline Often & 104 & 47.3 \\
\hline Always & 19 & 8.6 \\
\hline
\end{tabular}

ties in rural Transylvania in order to improve health outcomes and mitigate health disparities. Furthermore, having more than half of the same respondents not being involved in the development and the implementation phases, suggest that the programs which have been developed are conducted by external organisms without the support of local, key-actors like the local physicians. Even if these types of initiatives would lower the already considerable workload on physicians, it also increases the risk of developing programs which are not tailored or developed appropriately to the local needs and context.

Primary care doctors have been the initiators of health promotion campaigns in only $11.8 \%$ of the cases, revealing a low number of interventions designed by individuals within the community. Even if their considerable workload is acknowledged, in a country where public health practitioners and health communication specialists are scarce, few initiatives from the primary care sector results in a low overall number of evidence-based health campaigns. As a result, the need of capacity building in this field gives us a sense of urgency, especially in a country with limited resources like Romania.
More than half of the interviewed doctors reported that they often or always have patients who ask for additional health content information; more than half also report that they often or always feel the need for more informative health materials to offer to their patients. This emphasizes the need of informative materials which is absent in rural areas. Having health literature, print materials, brochures or pamphlets, made available to medical staff for distribution would be a low-cost intervention measure which could complement other activities. Furthermore, in the context in which the literacy rate in Romania is high, approximately $97.5 \%$, using print materials could be efficient in reaching target populations in rural and remote areas.

On the other hand, given these circumstances, only $4.6 \%$ of the doctors have actually used the communal library as a resource, in terms of recommending it to patients interested in more information on a health topic. Even though libraries and librarians could act as facilitators in health promotion, especially in rural and remote areas, by supporting access to health information, we can clearly see that they are hardly used in this sense in the studied area. This raises an important point in identifying culturally re- 
sponsive interventions in rural Romania, opening new research areas in physician-librarian cooperation for the improvement of population health. Thus, comprehensive interventions would not only offer infrastructure and updated informational health-content materials, but would also train and motivate librarians, as well as engage them in health promotion initiatives by stimulating the physician-librarian cooperation.

Finally, the non-governmental sector is very poorly represented in terms of getting involved in health promotion activities in rural areas. We showed throughout this paper that the overall rate of health promotion activities is low in the studied area, showing that governmental organizations do not meet the full range of activities that must be undertaken, in order to prevent diseases and promote health. On the other hand, the non-governmental sectors which should supply services that governmental organizations cannot offer for obvious reasons of resources constraints, was only responsible for organizing less than one tenth of all health promotion activities throughout the previous year. As a result, another systemic approach to the complex problem of improving population health would be the stimulation and support of this sector in getting involved in health promotion.

The authors of this paper acknowledge the limitations of the present study in terms of focusing analysis on data reported only by family physicians. However it also provides valuable information on health promotion practices and infrastructure in the understudied area of rural Transylvania. Finally, it reveals future research opportunities for this setting, in terms of mechanisms of empowering local actors in health promotion, like family physicians, librarians, and local governments, supporting and motivating the non-governmental sector in supplying for activities that governmental authorities cannot undertake, and finally, for providing evidence for the development of efficient, multi-level interventions to improve population health and mitigate health disparities.

\section{Acknowledgement}

The authors would like to acknowledge that this research project was financed through the "Access to Health Information in Rural Areas" Grant, funded by the Romanian Ministry of Education and Research, through the PNII-Idei Program, financing contract 772/2009.

\section{REFERENCES}

1. Ottawa charter for health promotion. First International Conference on Health Promotion. Ottawa 21 November 1986 - WHO/HPR/HEP/95.1 [Internet]. Geneva: WHO; 1986 [cited 2009 Sep 20]. Available from: www.who.int/hpr/NPH/docs/ottawa_charter_hp.pdf.

2. Nutbeam D. Health promotion glossary. Health Promot Int. 1988 Jan;13(4):349-64.

3. World Health Organization. Jakarta declaration on leading health promotion into 21st century [Internet]. Geneva: WHO; 1997 [cited 2009 Oct 15]. Available from: www.who.int/hpr/NPH/docs/jakarta_declaration_en.pdf.

4. McKee M, MacLehose L. Nolte E, editors. Health policy and European Union enlargement. European observatory on health systems and policies series. Buckingham: Open University Press; 2004.

5. European health for all database (HFA-DB) [Internet]. Copenhagen: WHO regional Office for Europe; 2009 [cited 2009 Oct 11]. Available from: http://www.euro.who.int/hfadb.

6. Mortality from selected causes of injury 2008 [Internet]. Copenhagen: WHO Regional Office for Europe [cited 2010 Jan 04]. Available from: http://www.euro.who.int/violenceinjury/ctryinfo/MortalityFromInjuries ?Country $=$ ROM $\&$ CtryName $=$ Romania.

7. WHO Statistical information system (WHOSIS) [Internet]. Geneva: World Health Organization; 2009 [cited 2009 Nov 15]. Available from: http://www.who.int/whosis/.

8. Pronk NP, Goodman MJ, O’Connor PJ, Martinson BC. Relationship between modifiable health risks and short-term health care charges. JAMA. 1999 Dec 15;282(23):2235-9.

9. Burke GL, Arnold AM, Bild DE, Cushman M, Fried LP, Newman A, et al; CHS Collaborative Research Group. Factors associated with healthy aging: the cardiovascular health study. J Am Geriatr Soc. 2001 Mar;49(3):254-62.

10. World Health Organization. World health assembly resolution WHA51.12 - Health promotion [Internet]. Geneva: WHO; 1998 [cited 2009 Nov 23]. Available from: http://www.who.int/healthpromotion/wha51-12/en/index. html.

11. Romanian Ministry of Public Health. National program for prevention [Internet]. Bucharest: Ministry of Public Health [cited 2010 Aug 12]. Available from http://www.ms.gov.ro/documente/6_51_327_a.htm. (In Romanian.)

12. Zeman C, Byrd B, Sinca A, Vlad M, Depken D. Health promotion theory, praxis and needs in Transylvania, Romania. Int Electron J Health Educ. 2005;8:36-47.

13. Baba CO, Brinzaniuc A, Sirlincan OE, Chereches RM. Access to health information in rural settings: the implementation of the libraries law no. 334/2002 in Transylvania, Romania. Transylvan Rev Adm Sci. 2010 Feb;(29E):30-8.

Received February 8, 2010 Accepted in revised form August 12, 2010 